\title{
FLOW VELOCITY OF CENTRAL RETINAL ARTERY AND RETROBULBAR VESSELS DURING CARDIOVASCULAR OPERATIONS
}

Kazumasa Orihashi, MD

Yuichiro Matsuura, MD

Taijiro Sueda, MD

Hiroo Shikata, MD

Satoru Morita, MD

Shinji Hirai, MD

Masafumi Sueshiro, MD

Kenji Okada, MD
Objective: Both blood flow monitoring and pressure monitoring are necessary to avoid inadequate cerebral perfusion during cardiovascular operations. Inasmuch as transcranial Doppler ultrasonography does not provide a consistently good signal, especially during cardiopulmonary bypass, we examined the blood flow through the central retinal artery, which has proved to reflect an obstruction of the carotid artery. Method: Twenty-eight consecutive cases were examined with a 5 or $7.5 \mathrm{MHz}$ conventional echocardiographic probe. Correlation between the maximal velocity at the central retinal artery and systolic blood pressure was examined. The blood flow of the central retinal artery and retrobulbar vessels was examined during selective or retrograde cerebral perfusion or intraaortic balloon pumping. Results: Blood flow could be clearly visualized but disappeared below a certain pressure in every case. With data from 478 measuring points, systolic blood pressure correlated with maximal velocity $(r=$ $0.6902, p<0.0001$ ). The blood pressure-axis intercept, known as "critical closing pressure," was $35.8 \pm 14.8 \mathrm{~mm} \mathrm{Hg}$, varying among individuals and bilateral eyes. Pulsatility index increased after cardiopulmonary bypass $(1.095 \pm 0.245$ to $1.525 \pm 0.268, p<0.0001)$. Patency of the circle of Willis was confirmed by the blood flow during anastomosis of the ipsilateral artery. During retrograde cerebral perfusion, blood flow was detectable at the retrobulbar vessels. During intraaortic balloon pumping, the central retinal artery flow was augmented on inflation of the balloon. Conclusion: Orbital vessel monitoring provides the critical closing pressure of the central retinal artery and confirms patency of the circle of Willis. The eye can be "an acoustic window" into intracranial blood flow during cardiovascular surgery. (J Thorac Cardiovasc Surg 1997;114:1081-7)
D uring cardiovascular operations, cerebral perfusion can be impaired by various factors, including nonpulsatile flow during cardiopulmonary bypass (CPB), circulatory arrest, surgical intervention to the branch arteries, intraoperative progression of aortic dissection, or an occurrence of embolism. When an unrecognized stenosis is present at the internal carotid artery, blood may steal to the upper extremities and external carotid arteries. Because a

From the First Department of Surgery, Hiroshima University School of Medicine, Hiroshima, Japan.

Received for publication Oct. 17, 1996; revisions requested Dec. 31, 1996; revisions received June 3, 1997; accepted for publication June 13, 1997.

Address for reprints: Kazumasa Orihashi, MD, First Department of Surgery, Hiroshima University School of Medicine, Kasumi 1-2-3, Minami-ku, Hiroshima, 734 Japan.

Copyright (C) 1997 by Mosby-Year Book, Inc.

$0022-5223 / 97 \$ 5.00+0 \quad \mathbf{1 2 / 1 / 8 4 0 8 5}$ complete preoperative study of intracranial and extracranial vessels on a routine basis is not practi$\mathrm{cal}$, an appropriate intraoperative monitor of blood flow is needed.

Transcranial Doppler ultrasonography is a noninvasive and inexpensive modality and can provide information on blood flow during surgery. However, it does not provide a consistently good signal, especially when the perfusion pressure is low. In such a situation, it is difficult to determine whether a signal change represents hypoperfusion or simply a technical problem. On the other hand, the introduction of color Doppler imaging has facilitated visualizing the orbital vessels, including the central retinal artery (CRA) and ophthalmic artery, and measuring their flow velocities. Several investigators have reported that an impaired CRA flow reflects stenosis or occlusion at the carotid artery. ${ }^{1,2}$ We have found that CRA flow disappears at a low perfusion pres- 


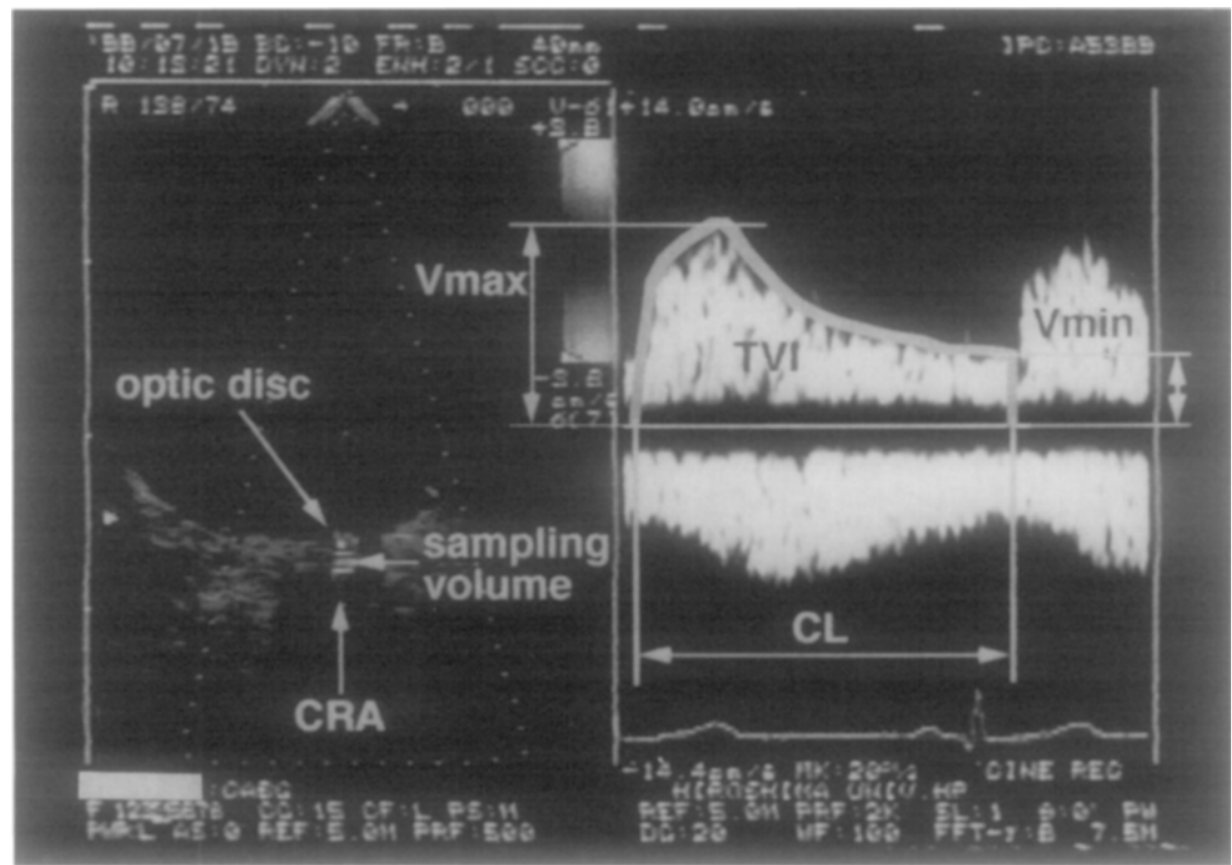

Fig. 1. Method of obtaining the flow velocity at the central retinal artery and measured parameters. The sampling volume was placed on the central retinal artery (CRA) 1 to $2 \mathrm{~mm}$ away from the optic disc. $V_{\max }$, Maximal velocity; $V_{\text {min }}$, minimal velocity; $T V I$, time velocity integral; $C L$, cycle length.

sure during surgery, and we considered that CRA flow monitoring could be used to detect inadequate cerebral perfusion. To our knowledge, no information regarding intraoperative changes of CRA flow is available in the literature.

In this study, we examined the changes of CRA flow, with particular focus on (1) the influence of blood pressure (BP) on the CRA blood flow velocity and (2) the CRA flow during selective cerebral perfusion, retrograde cerebral perfusion, or intraaortic balloon pumping.

\section{Subjects and methods}

We studied 28 consecutive cases of cardiovascular surgery with $\mathrm{CPB}$ in which an echocardiographer was available throughout the operation. The patients included 20 men and eight women, whose ages ranged from 44 to 82 years (average, 66.7 years). The operative procedures were coronary artery bypass grafting in 12 patients, aortic valve replacement in six, mitral valve replacement with or without tricuspid annuloplasty and maze operation in three (associated with aortic valve replacement in one), total arch replacement in four, and replacement of the descending aorta in four patients. Every patient was operated on by a single surgeon, with a single perfusionist. The $\mathrm{pH}$ was maintained according to an alpha-stat protocol. All data were collected and analyzed by a single investigator (Kazumasa Orihashi). The study was ap- proved by the institutional review board and informed consent was obtained from each patient.

After induction of anesthesia, the eyes were covered with a pair of adhesive patches (polyethylene, $0.12 \mathrm{~mm}$ thick, Me-Patch Clear L, Nichiban Co. Inc., Tokyo, Japan) and were visualized with a 5 or $7.5 \mathrm{MHz}$ echocardiographic system (EUP-S32, EUP-S33, EUB-555, Hitachi Medical Co. Inc., Tokyo, Japan). All data were recorded on S-VHS tapes with a videocassette recorder (BSS601M, Victor Co. Inc., Tokyo, Japan) for later analysis. The ultrasonic power was set to the lowest level to minimize damage to the ocular tissues. The eyes were scanned horizontally in color Doppler mode and the CRA was visualized with its course as parallel to the ultrasonic beam as possible. The sampling volume of $1 \mathrm{~mm}$ in length was placed on the CRA 1 to $2 \mathrm{~mm}$ away from the optic disc, and the flow velocity was recorded in pulsed-wave Doppler mode with the minimal wall filter of $100 \mathrm{~Hz}$, which corresponded to $0.96 \mathrm{~cm} / \mathrm{sec}$. The data were recorded for more than five beats, together with the updated systolic and diastolic BPs input on the screen.

Velocity, time, and area were measured with the use of graphic software, CANVAS version 3.02 (Deneba Systems Inc., Miami, Fla.), after a full screen image of the selected frame was copied to a Macintosh computer (Apple Computer, Cupertino, Calif.) in the PICT format with the same resolution as that of the original image without any modification. The horizontal and vertical scales in the image were used for calibration. The following parameters were measured (Fig. 1): 


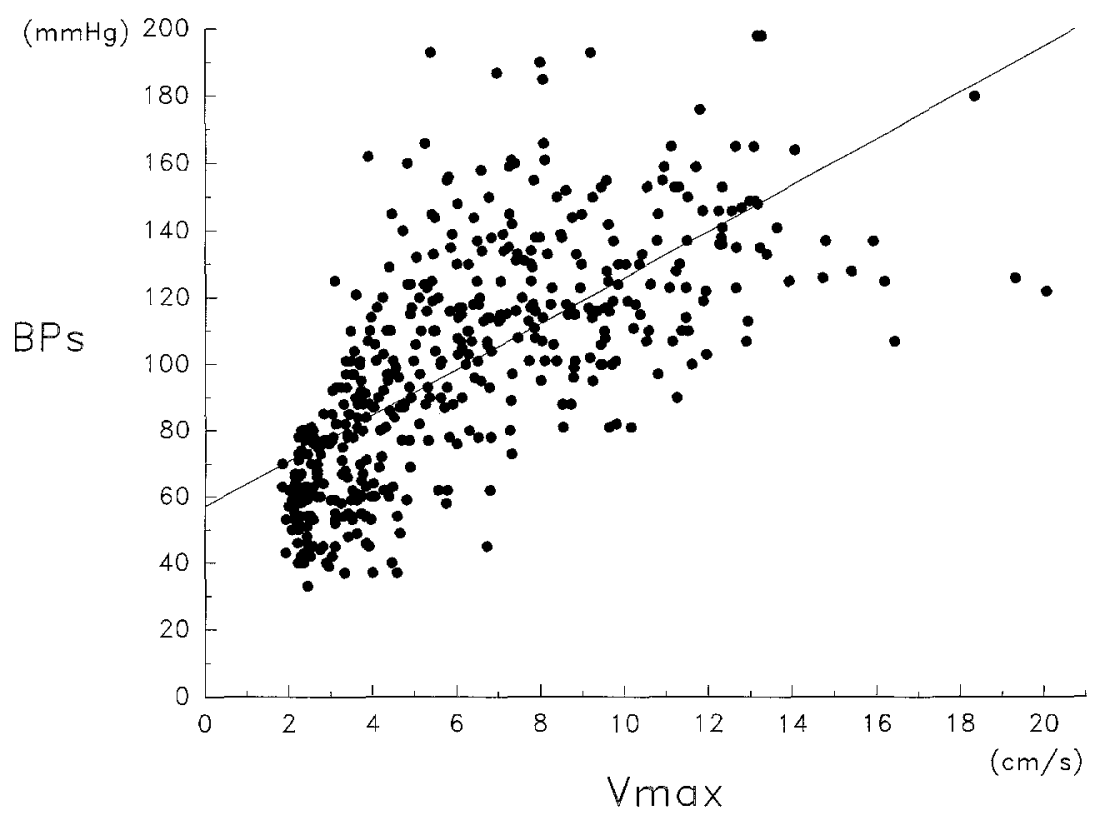

Fig. 2. Relationship between $\mathrm{V}_{\max }$ and systolic $\mathrm{BP}$ with all data of 478 measurement points. Systolic BP was significantly correlated with $\mathrm{V}_{\max }(r=0.6902, p<0.0001)$.

$\mathrm{V}_{\max }(\mathrm{cm} / \mathrm{sec})$ : The highest velocity of peak velocity envelope

$\mathrm{V}_{\min }(\mathrm{cm} / \mathrm{sec})$ : The lowest velocity of peak velocity envelope

Time velocity integral $(\mathrm{cm})$ : Area under peak velocity envelope

Cycle length $(\mathrm{sec})$ : Duration of the beat

$V_{\text {mean }}(\mathrm{cm} / \mathrm{sec})=($ Time velocity integral $) /($ Cycle length)

Pulsatility index $(\mathrm{PI})=\left(\mathrm{V}_{\max }-\mathrm{V}_{\min }\right) / \mathrm{V}_{\text {mean }}$

The value of each parameter at each measurement point was expressed as an average of data obtained at 5 beats. The data were excluded when a measurement was made within 30 minutes of the previous one but with a BP change of less than $10 \mathrm{~mm} \mathrm{Hg}(5 \mathrm{~mm} \mathrm{Hg}$ during CPB) or when the quality of the signal was apparently poor. When the PI was being examined, the data were excluded when $V_{\min }$ was smaller than $0.96 \mathrm{~cm} / \mathrm{sec}$ (cutoff value by the wall filter); when intraaortic balloon pumping was operative; or when the patient was supported by CPB. Consequently, analysis was done with data from 478 measurement points, including 237 points for assessing the PI. An average of PI in the prebypass and postbypass periods $\left(\mathrm{PI}_{\mathrm{pre}}, \mathrm{PI}_{\text {post }}\right)$ was calculated.

Correlation between the systolic $\mathrm{BP}$ and $\mathrm{V}_{\max }$ was examined with all data $(n=478)$ and at each CRA $(n=$ 56). The regression line (systolic $\mathrm{BP}=\alpha \cdot \mathrm{V}_{\max }+\mathrm{BP}_{0}$ ) was calculated when the number of samples was more than 4 and the correlation was significant $(p<0.01)$.

All data were expressed as the mean \pm standard deviation. Correlation was examined with Pearson's correlation coefficient and the statistical significance was examined by means of the $t$ test. Change of values after CPB was examined by the paired $t$ test. Statistical significance was determined when the $p$ value was smaller than 0.05 .

\section{Results}

No neurologic sequelae or manifest eye damage was encountered after the operation in any patient of this series. The CRA blood flow could be readily and clearly visualized and velocity could be measured in every case, except at low BP during CPB, the occurrence of which varied among individuals. As the perfusion pressure was lowered, the CRA became thinner in the color Doppler image, and below a certain pressure it became undetectable. On the other hand, several retrobulbar vessels were still visualized and became undetectable only at a much lower pressure. These changes were reversible in every case. Fig. 2 shows a significant correlation between $\mathrm{V}_{\max }$ and systolic BP based on the data of 478 measurement points $(r=0.6902, p<0.0001)$. The regression line was calculated in 29 CRAs of 18 patients with significant correlation $(p<0.01)$ and in the bilateral eyes in 11 patients. The $\mathrm{BP}_{0}$ of individual CRAs was $35.8 \pm 14.8 \mathrm{~mm} \mathrm{Hg}$, ranging from 3.3 to $71.6 \mathrm{~mm} \mathrm{Hg}$. The regression lines for bilateral CRAs were similar in nine patients, but there was a discrepancy in two patients (patient 10, a 70-year-old man undergoing aortic and mitral valve replacement and a maze operation; patient 12 , 


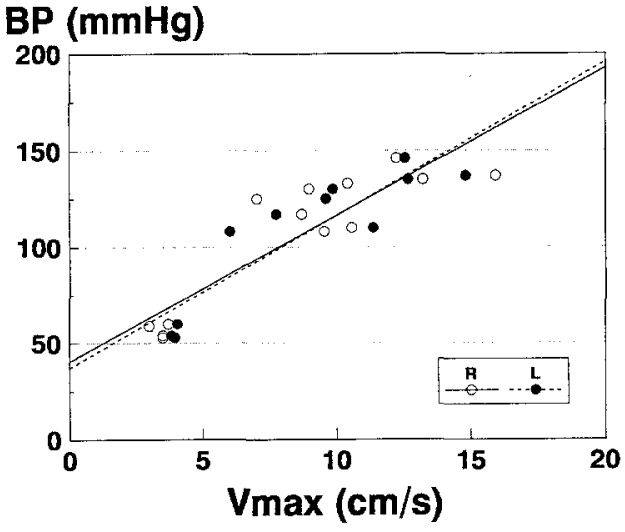

Case 5

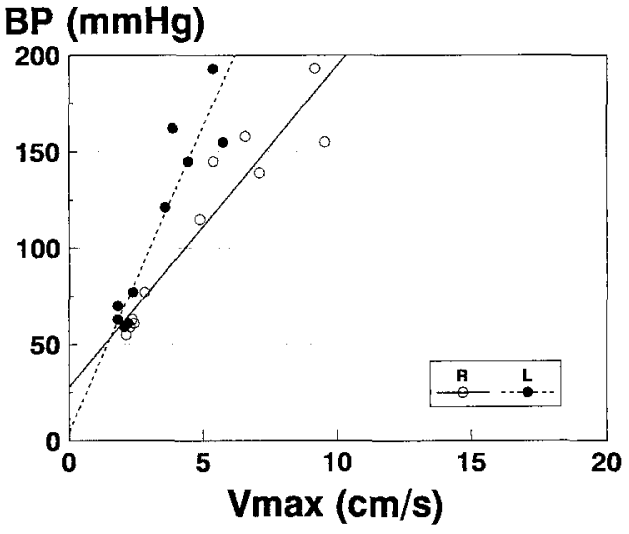

Case 12

Fig. 3. Discrepancy of systolic BP- $V_{\max }$ relationship between the right and left central retinal arteries. The regression lines were similar in case 5 (left) but were different in case 12 (right).

Table I. Detection of blood flow during selective cerebral perfusion by means of color Doppler mode

\begin{tabular}{|c|c|c|c|c|c|c|c|c|}
\hline & \multicolumn{8}{|c|}{ Patient } \\
\hline & \multicolumn{2}{|c|}{5} & \multicolumn{2}{|c|}{6} & \multicolumn{2}{|c|}{8} & \multicolumn{2}{|c|}{28} \\
\hline & $R$ & $L$ & $R$ & $L$ & $R$ & $L$ & $R$ & $L$ \\
\hline Before SCP & + & + & + & + & + & + & + & + \\
\hline SCP started & \pm & \pm & + & + & \pm & \pm & \pm & + \\
\hline Anastomosis of LSCA & NA & NA & + & + & \pm & \pm & \pm & \pm \\
\hline Anastomosis of LCCA & \pm & \pm & + & + & + & + & + & + \\
\hline Anastomosis of IA & + & + & + & + & $?$ & + & + & $?$ \\
\hline After reperfusion & + & + & + & + & + & + & + & + \\
\hline
\end{tabular}

$R$, Right; $L$, left; $S C P$, selective cerebral perfusion; $L S C A$, left subclavian artery; $L C C A$, left common carotid artery; $I A$, innominate artery; + , flow detected at central retinal artery; \pm , flow not detected at central retinal artery but detected at retrobulbar vessels; $N A$, not applicable because LSCA was not reconstructed; ?, data missing.

a 73-year-old woman undergoing coronary artery bypass grafting) (Fig. 3).

Both $\mathrm{PI}_{\text {pre }}$ and $\mathrm{PI}_{\text {post }}$ were obtained in 42 CRAs. The PI significantly increased after CPB $(1.095 \pm$ 0.245 to $1.525 \pm 0.268, p<0.0001$ ).

Selective cerebral perfusion was used in four patients with total arch replacement (patients 5, 6, 8, and 28). In these patients, selective cerebral perfusion was established and the distal anastomosis of the aorta was carried out under hypothermia at $20^{\circ} \mathrm{C}$ and systemic circulatory arrest. Then the left subclavian artery was reconstructed (not performed in patient 5) and the proximal anastomosis of the aorta performed, followed by anastomosis of the left common carotid and innominate arteries. The $\mathrm{V}_{\max }$ significantly correlated with systolic BP in all eight CRAs. The $\mathrm{BP}_{0}$ ranged from 24.8 to $40.5 \mathrm{~mm} \mathrm{Hg}$. The difference between bilateral CRAs was approximately $10 \mathrm{~mm} \mathrm{Hg}$ in two patients. The blood flow of
CRA and retrobulbar vessels was examined before and after initiation of selective cerebral perfusion and during and after anastomosis of each branch artery (Table I). During anastomosis of the common carotid and innominate arteries, blood flow continued through the retrobulbar vessels in every patient except at two measuring points for which the data was missing, indicating the presence of collateral flow via the circle of Willis.

Retrograde cerebral perfusion was used in two patients (patients 17 and 19) who underwent replacement of the descending aorta. During retrograde cerebral perfusion with the perfusion pressure of 5 to $25 \mathrm{~mm} \mathrm{Hg}$, blood flow toward the transducer was detected in the retrobulbar vessels, but not in the CRA. In patient 19, blood flow velocity of up to $5 \mathrm{~cm} / \mathrm{sec}$ was detected in the pulsed-wave Doppler mode (Fig. 4). This appears to be the retrograde flow in the orbital vein. 


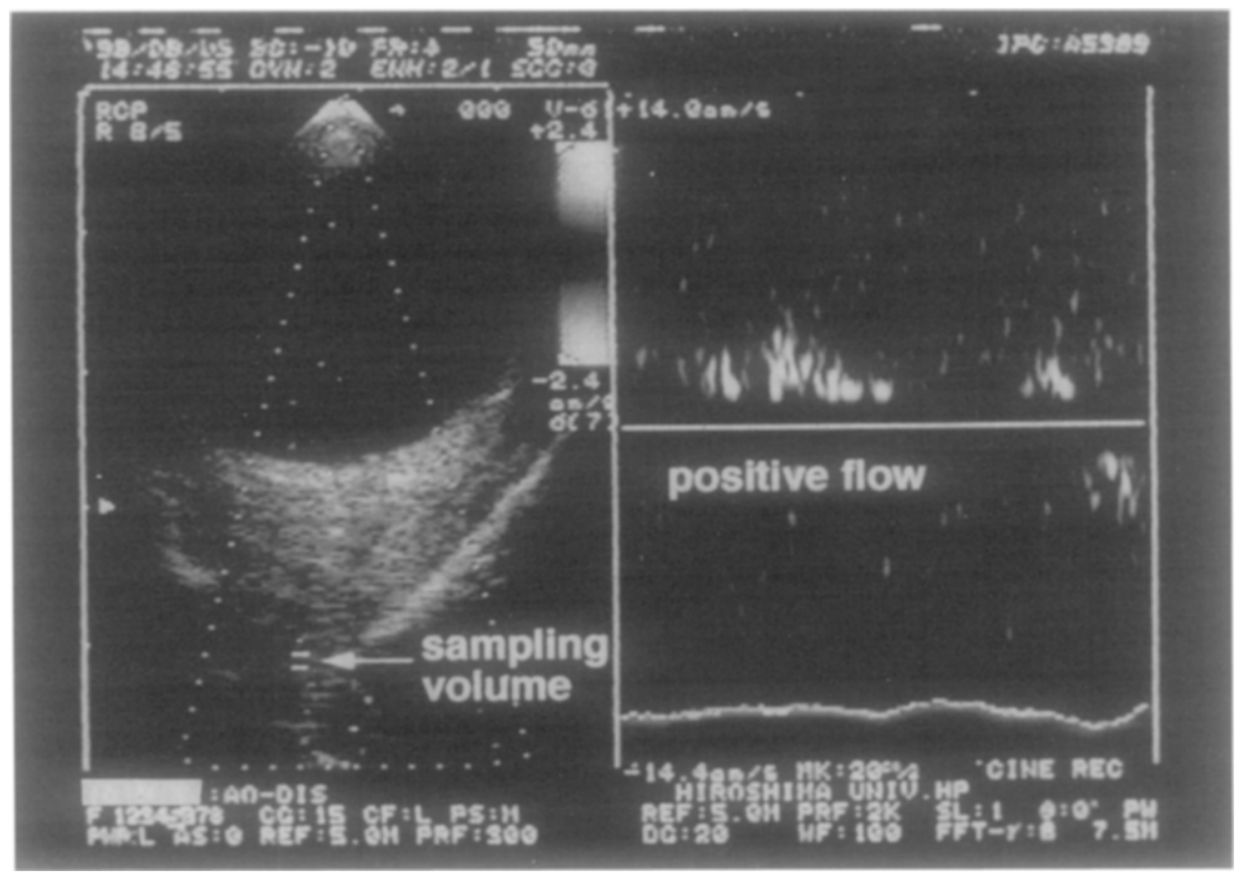

Fig. 4. Blood flow during retrograde cerebral perfusion. The blood flow toward the transducer was detected in the retrobulbar vessel, probably in the orbital vein.

Intraaortic balloon pumping was used in two patients (patients 15 and 21). While IABP was operative, diastolic augmentation was noted in the CRA flow velocity on balloon inflation (Fig. 5). When systemic BP was low, only the flow velocity generated by balloon inflation was detected.

\section{Discussion}

In this study, monitoring the blood flow in the CRA and orbital vessels provided two important points of information: $\mathrm{BP}_{0}$ of CRA and patency of the circle of Willis.

We have demonstrated that the blood flow in the orbital vessels is dependent on systolic BP. As the pressure decreases, the flow disappears in the CRA and then in the retrobulbar vessels. The $V_{\max }$ at CRA correlates with systolic BP in a broad range of systolic BPs including that of nonpulsatile flow during $\mathrm{CPB}$, as has been reported in healthy volunteers without $\mathrm{CPB} .{ }^{3}$ The regression line provides the systolic $\mathrm{BP}$ axis intercept, $\mathrm{BP}_{0}$, known as the "critical closing pressure" in transcranial Doppler examination. ${ }^{4}$ A perfusion pressure below the $\mathrm{BP}_{0}$ should result in de facto circulatory arrest at the CRA.

Because the ophthalmic artery arises from the carotid artery adjacent to the middle cerebral artery, a reduced flow in the CRA and retrobulbar vessels is likely to reflect the hypoperfusion of the ipsilateral hemisphere, unless there is an obstruction between the middle cerebral artery and ophthalmic artery. Because blood flow often remains detectable in the retrobulbar vessels at perfusion pressures below $\mathrm{BP}_{0}$, ischemia localized to the CRA-dependent region is likely to occur. If a similar situation is prolonged in the brain, diffuse ischemia at the vulnerable region might result, despite the fact that metabolism is reduced by $64 \%$ when the temperature is lowered by $10^{\circ} \mathrm{C} .5$ With an increased use of normothermic CPB, a concern for localized warm ischemia arises.

Kazui and associates ${ }^{6}$ recommended a selective cerebral perfusion rate of $10 \mathrm{ml} / \mathrm{kg}$ per minute with a perfusion pressure of 50 to $70 \mathrm{~mm} \mathrm{Hg}$.

Interestingly, this recommended pressure is just over the $\mathrm{BP}_{0}$ obtained in our study, $35.8 \pm 14.8 \mathrm{~mm}$ $\mathrm{Hg}$. It should be stressed, however, that the $\mathrm{BP}_{0}$ varied not only among individuals but between the two eyes of each individual. If $\mathrm{BP}_{0}$ of the CRA were related to the $\mathrm{BP}_{0}$ of the brain, the vulnerability to hypotension would be different among individual hemispheres.

During anastomosis of branch arteries, the blood flow of the dependent region is supplied by the contralateral internal carotid artery or vertebral 


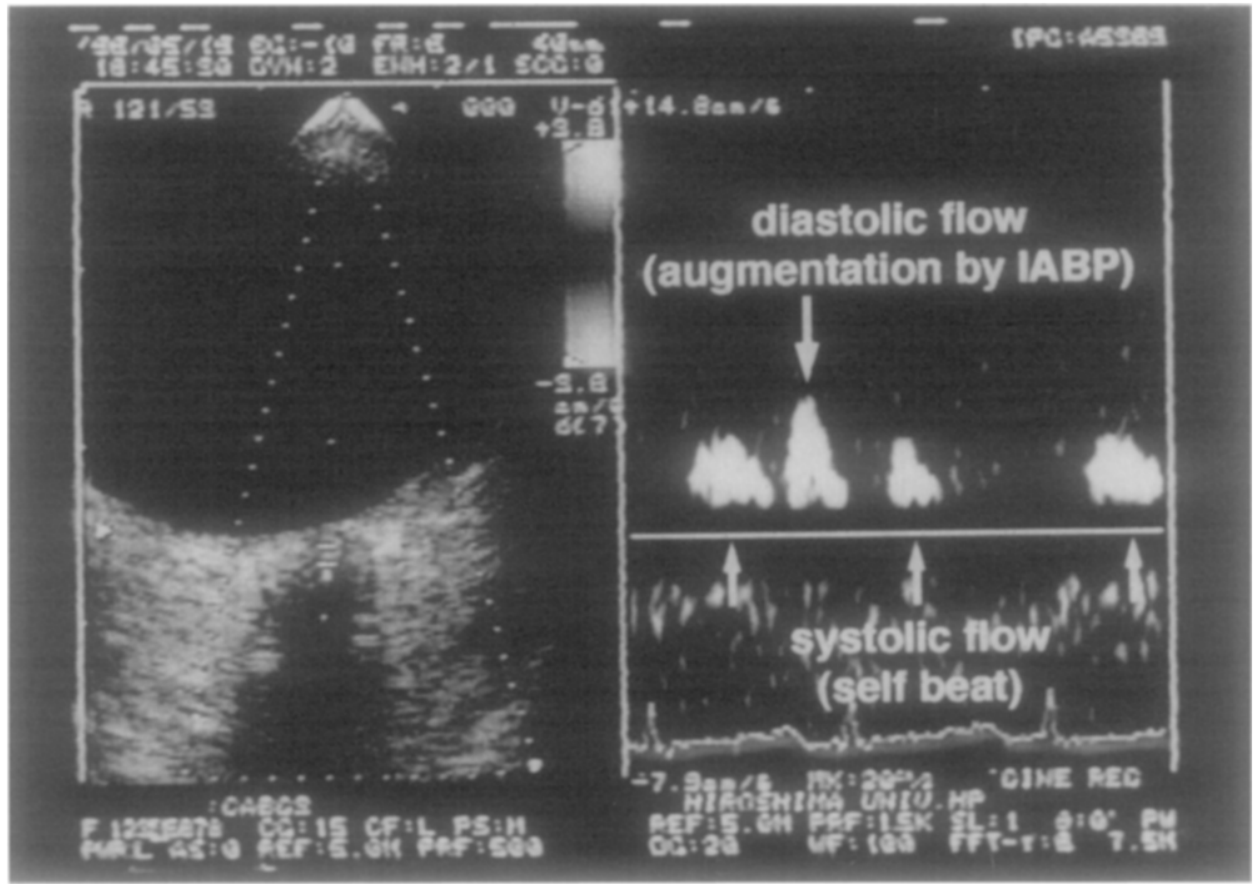

Fig. 5. Blood flow when intraaortic balloon pumping $(I A B P)$ was operative at a ratio of 2:1. The blood flow is augmented at inflation of the balloon.

artery through the circle of Willis. In case of inadequate collateral flow and unforeseen prolongation of the anastomosis, clamping the internal artery can result in ischemic damage, especially under moderate hypothermia at $28^{\circ} \mathrm{C} .^{6,7}$ The presence of CRA blood flow during crossclamping confirms the patency of the circle of Willis. If the collateral flow is inadequate, the crossclamping time should be minimized.

$\mathrm{PI}^{8}$ is one of the commonly used indices in transcranial Doppler ultrasonography. A reduced PI value indicates reduced peripheral resistance and/or presence of obstruction at the proximal portion of the artery. ${ }^{9}$ The current study showed an increase in PI after CPB, possibly caused by edematous changes of tissues.

In retrograde cerebral perfusion, which is an alternate method for protecting the brain during aortic arch repair, the valves of the internal jugular vein can compromise the perfusion of intracranial vessels. ${ }^{10,11}$ Sakahashi and associates, ${ }^{12}$ using transcranial Doppler ultrasonography, detected middle cerebral artery flow during retrograde cerebral perfusion, but only in three of six patients. In our study, blood flow was detected in the retrobulbar vessels in both cases of retrograde cerebral perfusion. It is not clear, however, whether the presence of orbital blood flow reflects an adequate cerebral perfusion during retrograde perfusion. A further study with a large number of cases is mandatory to evaluate the significance of this finding.

CRA monitoring has the advantages of being noninvasive, inexpensive, and in real time, like transcranial Doppler ultrasonography. It also saves space in the operating theater, because it shares a system with transesophageal echocardiography, which has become a routine monitoring device during cardiovascular operations.

Several limitations of this study should also be mentioned. First, the reliability of CRA monitoring is not compared with that of transcranial Doppler ultrasonography, which is considered to be the standard technique for assessing the intracranial blood flow. Because no report had been available regarding CRA flow monitoring, we considered it essential to examine the behavior of CRA flow during cardiovascular operations with widely varying systolic BPs before comparing the CRA-derived data with Doppler-derived data and assessing the clinical relevance of CRA monitoring to the neurologic sequelae. In transcranial Doppler ultrasonography, a signal of good quality is not consistently obtained or may take significant time to detect the flow, especially at a low perfusion pressure. Nuttall 
and coworkers ${ }^{13}$ reported that velocity of flow through the middle cerebral artery could be determined during CPB in only 12 of 16 patients. When the flow cannot be detected, it is unclear whether this is due to technical problems or decreased flow velocity.

Although $\mathrm{BP}_{0}$ could be obtained in only 18 of 28 patients in this series, this was mainly due to the small number of measuring points remaining after the exclusion of several data by the aforementioned criteria. When a larger number of data were available, as in patients with selective cerebral perfusion, the correlation was significant.

We selected the CRA among several vessels in the orbit, because it is one of the two most reliable vessels for assessing reproducible blood flow, ${ }^{14}$ the other being the ophthalmic artery. The former is depicted clearly in color Doppler mode with minimal attenuation of ultrasound through the vitreous body as an acoustic window. The optic disc acts as a landmark for identifying the CRA. The sampling volume was placed 1 to $2 \mathrm{~mm}$ away from the optic disc, where the highest velocity is obtained. ${ }^{15}$ Unlike the situation with transcranial Doppler ultrasonography, little training is needed for visualizing the CRA and for measuring the blood flow.

Ultrasonography can potentially damage orbital tissues by exposing them to energy or heat. When transcranial Doppler ultrasonography is used in the transorbital approach, the power output must be reduced to a level lower than $10 \%$ of that in other approaches. The Food and Drug Administration has recommended that the ultrasonic output be lower than 17 ISPTA $\left(\mathrm{mW} / \mathrm{cm}^{2}\right)$ for observing the eye, but that it may be increased up to 720 ISPTA in track 3 (when supervised by a physician). We used an ultrasound system with an output setting of 200 ISPTA in Doppler mode. The main damage from ultrasonography results from elevating the temperature of the tissue, which seems less significant in cases under hypothermia. However, it is recommended that prolonged exposure of orbital tissues to ultrasonography be avoided and that the examinations should be performed intermittently.

In conclusion, monitoring the CRA flow velocity provided the critical closing pressure of CRA and patency at the circle of Willis in each individual case. The eye can be an "acoustic window," providing an additional monitor of intracranial blood flow during cardiovascular surgery, and especially during CPB.

\section{REFERENCES}

1. Lieb WE, Flaharty PM, Sergott RC, Medlock RD, Brown GC, Bosley T, et al. Color Doppler imaging provides accurate assessment of orbital blood flow in occlusive carotid artery disease. Ophthalmology 1991;98:548-52.

2. Peternel P, Keber D, Videcnik V. Carotid arteries in central retinal vessel occlusion as assessed by Doppler ultrasound. Br J Ophthalmol 1989;73:880-3.

3. Williamson $\mathrm{TH}$, Lowe GD, Baxter GM. Influence of age, systemic blood pressure, smoking, and blood viscosity on orbital blood velocities. Br J Ophthalmol 1995;79:17-22.

4. Aaslid R. Cerebral hemodynamics. In: Newell DW, Aaslid R, editors. Transcranial Doppler. New York: Raven Press; 1992. p. $49-55$.

5. Croughwell N, Smith LR, Quill T, Newman M, Greeley W, Kern F, et al. The effect of temperature on cerebral metabolism and blood flow in adults during cardiopulmonary bypass. J Thorac Cardiovase Surg 1992; 03:549-54.

6. Kazui T, Inoue N, Yamada O, Komatsu S. Selective cerebral perfusion during operation for aneurysms of the aortic arch: a reassessment. Ann Thorac Surg 1992;53:109-14.

7. Tabayashi K, Niibori K, Iguchi A, Shoji Y, Ohmi M, Mohri $\mathrm{H}$, et al. Replacement of the transverse aortic arch for type $\mathrm{A}$ acute aortic dissection. Ann Thorac Surg 1993;55:864-7.

8. Gosling RG, King DH. Arterial assessment by Doppler shift ultrasound. Proc R Soc Med 1974;67:447-9.

9. Lindegaard KF. Indices of pulsatility. In: Newell DW, Aaslid R, editors. Transcranial Doppler. New York: Raven Press; 1992. p. 67-82.

10. Usui A, Hotta T, Hiroura M, Murase M, Maeda M, Koyama $\mathrm{T}$, et al. Retrograde cerebral perfusion through a superior vena caval cannula protects the brain. Ann Thorac Surg 1992;53:47-53.

11. Saf HJ, Brien HW, Winter JN, Thomas AC, Maulsby RL, Doerr HK, et al. Brain protection via cerebral retrograde perfusion during aortic arch aneurysm repair. Ann Thorac Surg 1993;56:270-6.

12. Sakahashi H, Hashimoto A, Aomi S, Tokunaga H, Koyanagi $\mathrm{T}$, Imamaki $\mathrm{M}$, et al. Transcranial Doppler measurement of middle cerebral artery blood flow during continuous retrograde cerebral perfusion. Nippon Kyobu Geka Gakkai Zasshi 1994;42:1851-7.

13. Nuttall GA, Gook DJ, Fulgham JR, Oliver WC Jr, Proper JA. The relationship between cerebral blood flow and transcranial Doppler blood flow velocity during hypothermic cardiopulmonary bypass in adults. Anesth Analg 1996;82: 1146-51.

14. Baxter GM, Williamson TH. Color Doppler imaging of the eye: normal ranges, reproducibility, and observer variation. $\mathbf{J}$ Ultrasound Med 1995;14:91-6.

15. Dennis KJ, Dixon RD, Winsberg F, Ernest JT, Goldstick TK. Variability in measurement of central retinal artery velocity using color Doppler imaging. J Ultrasound Med 1995;14: 463-6. 